\title{
Traumatic spinal cord injuries in Southeast Turkey: an epidemiological study
}

\author{
ŞS Karamehmetoğlu ${ }^{1}, \mathrm{~K} \mathrm{Nas}^{2}$, I Karacan ${ }^{1}$, AJ Sarac ${ }^{2}$, H Koyuncu ${ }^{1}$, S Ataoğlu² and F Erdoğan ${ }^{2}$ \\ ${ }^{1}$ Istanbul University, Cerrahpașa Medical Faculty, Physical Medicine \& Rehabilitation Dept. Istanbul; ${ }^{2}$ Dicle \\ University Medical Faculty, Physical Medicine and Rehabilitation Dept. Diyarbakir, Turkey
}

\begin{abstract}
In 1994, a retrospective study of new cases of traumatic Spinal Cord Injury (SCI) was conducted in all the hospitals in Southeast Turkey: 75 new traumatic SCI were identified. The estimated annual incidence was 16.9 per million population. The male/female ratio was 5.8/1. The mean age was 31.3 , being 31.25 for male patients and 31.36 for female patients. $70.7 \%$ of all patients were under the age of 40 . The major causes of SCI were falls $(37.3 \%)$ and gunshot wounds $(29.3 \%)$, followed by car accidents $(25.3 \%)$, and stab wounds $(1.3 \%)$. Thirty one patients $(41.3 \%)$ were tetraplegic and $44(58.7 \%)$ paraplegic. In tetraplegic patients the commonest level was $\mathrm{C} 5$, in those with paraplegia L1. The commonest associated injury was head trauma followed by fractures of the extremity(ies). Severe head trauma, being a major cause of death, may have obscured the actual incidence of SCI. Most of gunshot injured SCI patients were young soldiers fighting against the rebels. As there was no available data for the rebels with SCI, the actual incidence of SCI in Southeast (SE)Turkey should be higher than that found in this study.
\end{abstract}

Keywords: Spinal cord injury (SCI); epidemiology; incidence; Southeast Turkey

\section{Introduction}

In Turkey, there has only been one epidemiological study of SCI conducted in Istanbul. ${ }^{1}$ It was considered that a similar study would be important for SE Turkey.

\section{Material and methods}

In 1994, the population of Southeast of Turkey was $4,416,336^{2}$. We conducted this retrospective study for the year 1994. Records of SCI patients were obtained from the emergency services, intensive care units and departments of orthopaedic surgery and neurosurgery and rehabilitation medicine.

\section{Results}

Incidence

The annual incidence (1994) of traumatic SCI was 16.9 per million population.

Gender and age

There were 64 males and 11 females with SCI, the male/female ratio being 5.8/1. The mean age was $31.3 \pm 12.8$, being $31.2 \pm 13.0$ for male patients and $31.4 \pm 11.7$ for females. SCI was most prevalent

Correspondence: Ass Prof Şafak S Karamehmetoğlu, MD between 20-29 years inclusive with only one peak in this age group (Figure 1). But when we considered the incidence by age groups, the most prevalent age group was $40-49$ followed by 20-29 years inclusive (Figure 2).

\section{Causes of SCI}

In this study, falls exceeded gunshots and road accidents as causes of SCI. Falls, gunshots and road accidents altogether accounted for $91.9 \%$ of all causes. Other causes were being struck by an object $(5.2 \%)$, stab injury $(1.3 \%)$, suicide $(1.3 \%)$.

Falls were more common in middle age groups; gunshot wounds in younger people; and road accidents in older age groups.

SCI level

Thirty one patients $(41.3 \%)$ were tetraplegic and 44 $(58.7 \%)$ paraplegic. In tetraplegic patients the commonest level was C5, in paraplegic L1.

\section{Associated trauma}

Thirty eight percent of the patients had associated trauma, the commonest being head injury, followed by extremity fractures, pneumothorax, hemothorax, and burns. 


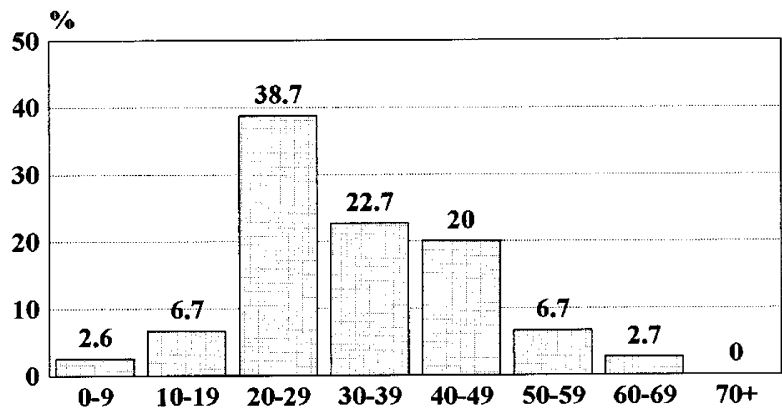

Figure 1 Distribution of SCI by age groups

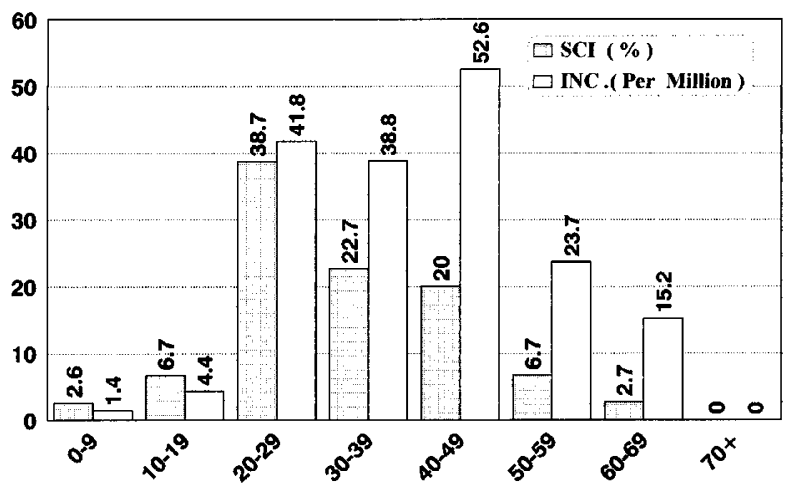

Figure 2 Incidence and distribution of SCI by age groups

\section{Discussion}

On comparison of the incidence of SCI in the literature, we found that it ranged from six to 56.1 per million population. ${ }^{1,3-12}$ (Figure 3). We also saw that there were considerable differences within one country e.g. USA and Taiwan. This might be due to methodological, demographic, sociological, geographical and political factors. The incidence of SCI in Southeast Turkey (a rural area) was lower than that in Istanbul, the most populated city of Turkey. SCI appeared to increase with civilisation. In developed countries such as USA, Japan, Germany the incidence of SCI was found to be high. $5,8,9,11$

As in most of the studies, SCI was commonest in the 20-29 age group. Turkey has a very young population, and the 20-29 age group is the most prominent. This period of life is characterised by high risk activities such as fighting, driving and climbing, and therefore it appears normal to have the highest incidence of SCI in this age group. Consideration of the incidence by age groups we found the highest incidence to be in the $40-49$ age group (52.6 per million).

Although there were almost equal numbers of males and females in the population, SCI was six times commoner in males than in females; and as is also reported in other studies, males are at a greater risk of SCI. ${ }^{1,3-12}$ In a developing country such as Turkey men are the breadwinners, often working in potentially

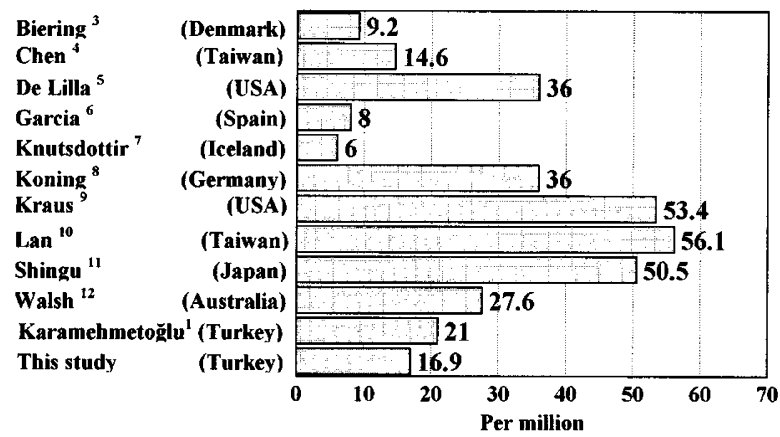

Figure 3 Incidence of SCI in the literature

dangerous situations, and they drive cars. On the other hand women are usually at home as housewives, and are protected from many outside dangers.

Head trauma as a common cause of death might obscure the actual incidence of SCI. It was estimated that $12-15 \%$ of deaths at the time of admission to hospital were associated with SCI $^{13,14}$ : mainly due to head and brain injury, followed by cardiopulmonary problems.

This study differed from other studies in that falls and gunshot wounds exceeded road accidents as main causes of SCI. In most of the literature road accidents were the major cause of SCI. ${ }^{1,3-6,15}$ SCI from falls appeared to be a feature in developing countries. ${ }^{16-17}$ As a second cause of SCI, gunshot injury would be a specific finding in those parts of Turkey that are conflict areas. As there is no available data for the rebels with SCI, the actual incidence of SCI in the Southeast of Turkey would be higher than that found in this study.

\section{References}

1 Karamehmetoğlu ȘS et al. Traumatic spinal cord injuries in Istanbul, Turkey. An epidemioligical study. Paraplegia 1995; 33: $469-471$.

2 State Institute of Statistics Prime Ministry, Republic of Turkey. Statistical year-book of Turkey, 1992.

3 Biering-Sorensen F, Pedersen V, Clausen S. Epidemiology of spinal cord lesions in Denmark. Paraplegia 1990; 28: 105-118.

4 Chen CF, Lien IN. Spinal cord injuries in Taipei, Taiwan: $1978-$ 81. Paraplegia 1985; 23: $364-370$.

5 De Lilla T, Eddy S, Cooper T, Hensley K. Five year summary on spinal cord injuries statistics, Florida, 1990.

6 Garcia-Renses J, Herruzo Cabrera R, Martinez-Moreno. M. Epidemiological study of spinal cord injury in Spain 1984-1985. Paraplegia 1991; 28: $180-190$.

7 Knutsdottir S. Spinal cord injuries in Iceland: 1973-1989. A follow-up Study. Paraplegia 1993; 31: 68-72.

8 Konig W, Frowein RA. Incidence of spinal cord injuries in the Federal Republic of Germany. Neurosurg Rev 1989; 12: $562-566$.

9 Kraus JF et al. Incidence of traumatic spinal cord lesions. J Chron Dis 1975; 28: 471 - 492 .

10 Lan C et al. Traumatic spinal cord injuries in the rural region of Taiwan: An epidemiological study in Hualien Country, $1986-$ 1990. Paraplegia 1993; 31: $398-403$.

11 Shingu H, Ikata T, Katoh S, Akatsu T. Spinal cord injuries in Japan: A nationwide epidemiological survey in 1990. Paraplegia 1994; 32: 3-8. 
12 Walsh JE. Costs of Spinal Cord Injury in Australia. Paraplegia 1988; 26: $386-388$.

13 Wilmot CB, Cope DN, Hall KM, Acker M. Occult head injury: its incidence in spinal cord injury. Arch Phys Med Rehabil 1985; 66: $227-231$

14 Davidoff $\mathrm{G}$ et al. Closed head Injury in acute traumatic spinal cord injury: incidence and risk factors: Arch Phys Med Rehabil 1988; 69: $869-872$.

15 Tator $\mathrm{CH}$ et al. Changes in epidemiology of spinal cord injury from 1947 to 1981. Surg Neurol 1993; 40: 207-215.
16 Marshall A, Chahal AS, Fraks MS, Chabbra HS. Pattern of spinal cord injuries in Delhi. 33rd annual scientific meeting of the International Medical Society of Paraplegia, 30 May-2 June Kobe Japan, 1994 Abstracts: 57.

17 Silberstein B, Rabinovic S. Epidemiology of spinal cord injuries in Novosibirsk in Delhi. 33rd annual scientific meeting of the International Medical Society of Paraplegia, 30 May-2 June Kobe Japan, 1994 Abstracts: 149. 